Bull. Chem. Soc. Ethiop. 2020, 34(1), 123-134.

ISSN 1011-3924

(C) 2020 Chemical Society of Ethiopia and The Authors

Printed in Ethiopia

DOI: https://dx.doi.org/10.4314/bcse.v34i1.11

\title{
SYNTHESIS OF Ag-Fe $\mathrm{O}_{4}$ NANOPARTICLES FOR DEGRADATION OF METHYLENE BLUE IN AQUEOUS MEDIUM
}

\author{
Muhammad Saeed*, Muhammad Usman, Majid Muneer, Nadia Akram, Atta ul Haq, \\ Muhammad Tariq and Fiza Akram \\ Department of Chemistry, Government College University Faisalabad, Jhang Road, Faisalabad \\ Pakistan
}

(Received September 8, 2019; Revised December 19, 2019; Accepted January 29, 2020)

\begin{abstract}
Fe}_{3} \mathrm{O}_{4}$ known as magnetite is one of the oxides of iron which plays a major role in various fields of sciences. $\mathrm{Fe}_{3} \mathrm{O}_{4}$ was synthesized by precipitation method using $\mathrm{NH}_{3} \cdot \mathrm{H}_{2} \mathrm{O}, \mathrm{FeCl}_{2} \cdot 4 \mathrm{H}_{2} \mathrm{O}$ and $\mathrm{FeCl}_{3} \cdot 6 \mathrm{H}_{2} \mathrm{O}$ as precursor materials. For synthesis of $5 \% \mathrm{Ag}-\mathrm{Fe}_{3} \mathrm{O}_{4}$, the green synthetic method was used for immobilization of $\mathrm{Ag}$ nanoparticles on $\mathrm{Fe}_{3} \mathrm{O}_{4}$ using leaves extract of Calotropis gigantea plant. The synthesized $\mathrm{Fe}_{3} \mathrm{O}_{4}$ and $5 \% \mathrm{Ag}-\mathrm{Fe}_{3} \mathrm{O}_{4}$ were employed as catalyst in degradation of methylene blue. The photo catalytic activity of $\mathrm{Fe}_{3} \mathrm{O}_{4}$ was remarkably enhanced by doping of $\mathrm{Fe}_{3} \mathrm{O}_{4}$ with $\mathrm{Ag}$ nanoparticles. Advanced instrumental techniques including XRD, EDX, TGA and SEM were used for characterization of synthesized particles. The immobilization of $\mathrm{Ag}$ on $\mathrm{Fe}_{3} \mathrm{O}_{4}$ enhanced the photo degradation of methylene blue from 40 to $72 \%$ at $40{ }^{\circ} \mathrm{C}$ which confirms that $5 \% \mathrm{Ag}-\mathrm{Fe}_{3} \mathrm{O}_{4}$ is an active catalyst for treatment of dye contaminated water. $\mathrm{Ag}-\mathrm{Fe}_{3} \mathrm{O}_{4}$ exhibited almost same catalytic activity in two successive cycles.
\end{abstract}

KEY WORDS: $\mathrm{Fe}_{3} \mathrm{O}_{4}$, Calotropis gigantea, Degradation, Methylene blue

\section{INTRODUCTION}

A large number of elements are known which are plentiful in occurrence and extensively used on earth. Iron, in the form of various oxides, is one of these known elements which has potential for different applications. Various types of oxides of $\mathrm{Fe}$ like $\mathrm{Fe}_{3} \mathrm{O}_{4}, \beta-\mathrm{Fe}_{2} \mathrm{O}_{3}, \alpha-\mathrm{Fe}_{2} \mathrm{O}_{3}$ and $\mathrm{FeO}$ are known to exist. These polymorphs of iron oxide exhibit remarkable chemical and physical properties which are favorable in wide range of applications. These magnetic nanoparticles of iron oxides have many uses such as recording material, magnetic resonance imaging, magnetic drug target, environment and catalysts [1]. $\mathrm{Fe}_{3} \mathrm{O}_{4}$ known as magnetite is one of the oxides of iron which plays a major role in various areas of chemistry, material sciences, physics and medical sciences. $\mathrm{Fe}_{3} \mathrm{O}_{4}$ crystallizes in mixed oxidation state iron $\left(\mathrm{Fe}^{3+}\right.$ and $\left.\mathrm{Fe}^{2+}\right)$ inverse cubic spinel structure [2-4]. $\mathrm{Fe}_{3} \mathrm{O}_{4}$ can be used in magnetic resonance imaging, in drug delivery systems, as sorbent for heavy metal, as antibacterial agents, as catalyst, as electrochemical biosensors, as shielding material in electromagnetic interference and for energy harvesting [5-9]. It has been reported that separation between valence band of $\mathrm{Fe}(4 \mathrm{~s})$ and $\mathrm{O}(2 \mathrm{p})$ in $\mathrm{Fe}_{3} \mathrm{O}_{4}$ is $4-6$ $\mathrm{eV}(309-206 \mathrm{~nm})$ [10]. Hence, $\mathrm{Fe}_{3} \mathrm{O}_{4}$ can be confidently tested as photo catalyst for remediation of aqueous contaminants under ultra violet/visible irradiation. The photo catalytic activity of metal oxide, $\mathrm{Fe}_{3} \mathrm{O}_{4}$, can be further boosted up by doping it with metal atoms. In metal-metal oxide photo catalyst, the photo excited electron easily shifts to fermi level of doped metal atom via Schottky contact which prevents the de-excitation of electron and hence it improves the catalytic performance of metal oxide [11-13]. In this study we have made an attempt to develop an effective photo catalyst for degradation of methylene blue in aqueous medium.

*Corresponding author. E-mail: msaeed@gcuf.edu.pk

This work is licensed under the Creative Commons Attribution 4.0 International License 


\section{EXPERIMENTAL}

Synthesis of $\mathrm{Fe}_{3} \mathrm{O}_{4}$

Chemical coprecipitation method was used for synthesis of $\mathrm{Fe}_{3} \mathrm{O}_{4}$ nanoparticles using $\mathrm{NH}_{4} \mathrm{OH}$, $\mathrm{FeCl}_{2} \cdot 4 \mathrm{H}_{2} \mathrm{O}$ and $\mathrm{FeCl}_{3} \cdot 6 \mathrm{H}_{2} \mathrm{O}$ as precursor materials. A solution was prepared by suspending $16.25 \mathrm{~g} \mathrm{FeCl}_{3} \cdot 6 \mathrm{H}_{2} \mathrm{O}$ in $100 \mathrm{~mL}$ distilled water. Similarly, another solution was prepared by suspending $6.35 \mathrm{~g} \mathrm{FeCl}_{2} .4 \mathrm{H}_{2} \mathrm{O}$ in $100 \mathrm{~mL}$ distilled water. Both solutions were mixed in a glass beaker. Then, $\mathrm{NH}_{4} \mathrm{OH}$ was added dropwise to mixture formed by mixing of first two solutions of $\mathrm{FeCl}_{3} \cdot 6 \mathrm{H}_{2} \mathrm{O}$ and $\mathrm{FeCl}_{2} \cdot 4 \mathrm{H}_{2} \mathrm{O}$ under continuous stirring at $70{ }^{\circ} \mathrm{C}$ till $\mathrm{pH} 10$. The resultant precipitate was filtered, washed and dried. The chemical reaction can be expressed as:

$$
2 \mathrm{FeCl}_{3}+\mathrm{FeCl}_{2}+8 \mathrm{NH}_{4} \mathrm{OH} \rightarrow \mathrm{Fe}_{3} \mathrm{O}_{4}+4 \mathrm{H}_{2} \mathrm{O}+8 \mathrm{NH}_{4} \mathrm{Cl}
$$

Synthesis of $\mathrm{Ag}_{-} \mathrm{Fe}_{3} \mathrm{O}_{4}$

Green synthetic method using leaves extract of Calotropis gigantea was used for reduction of $\mathrm{Ag}$ ions in synthesis of $5 \% \mathrm{Ag}_{-} \mathrm{Fe}_{3} \mathrm{O}_{4}$. For this purpose, a $50 \mathrm{~mL}$ plant extract obtained by boiling dried leaves $(15 \mathrm{~g})$ in distilled water was dropped to a suspension containing a predetermined amount of $\mathrm{Fe}_{3} \mathrm{O}_{4}$ prepared in first step and $\mathrm{AgNO}_{3}$. After stirring the suspension for $120 \mathrm{~min}$, the solid residue was filtered, washed and dried. The obtained powder consisting of $5 \% \mathrm{Ag}-\mathrm{Fe}_{3} \mathrm{O}_{4}$ was preserved for further analyses.

\section{Characterization}

Advanced instrumental techniques including XRD, EDX, TGA and SEM were used for characterization of $\mathrm{Fe}_{3} \mathrm{O}_{4}$ and $\mathrm{Ag}-\mathrm{Fe}_{3} \mathrm{O}_{4}$ with JDX-3532 X-Ray Diffractometer (Japan), EDX JSM5910 (UK), Perkin Elmer 6300 TGA Analyzer (USA) and JSM-5910 (Japan), respectively.

\section{Degradation procedure}

The photo degradation of methylene blue over $\mathrm{Fe}_{3} \mathrm{O}_{4}$ and $\mathrm{Ag}-\mathrm{Fe}_{3} \mathrm{O}_{4}$ was conducted in a Pyrex glass beaker as batch reactor as we reported earlier [13]. For this purpose, a mixture of methylene blue solution and synthesized catalyst was stirred for 15 min in dark. Afterward, the photo reactor was irradiated with visible light in the presence of $\mathrm{O}_{2}$. A photo reacted suspension was taken periodically and analyzed with UV-visible spectrophotometer for concentration of methylene blue.

\section{RESULTS AND DISCUSSION}

\section{Characterization}

The crystalline structure of prepared nano particles of $\mathrm{Fe}_{3} \mathrm{O}_{4}$ and $\mathrm{Ag}-\mathrm{Fe}_{3} \mathrm{O}_{4}$ were determined by powder X-rays analyses. The XRD of synthesized $\mathrm{Fe}_{3} \mathrm{O}_{4}$ and $\mathrm{Ag}-\mathrm{Fe}_{3} \mathrm{O}_{4}$ is dominated with sharp peaks confirming the crystallinity of prepared particles (Figure 1). The XRD pattern shows diffraction peaks at $2 \theta 30.88,35.47,42.87,54.28,57.76$ and $62.98^{\circ}$ which correspond to (2-0$0),(3-1-1),(4-0-0),(4-2-2),(5-1-1)$ and (4-4-0) hkl planes of $\mathrm{Fe}_{3} \mathrm{O}_{4}$, respectively [3]. According to JCPDS No. 03-0863, all the diffraction peaks observed in XRD pattern can be indexed to cubic structure of $\mathrm{Fe}_{3} \mathrm{O}_{4}$. Wang et al. [14] have assigned these diffraction peaks to (1-0-4), (1-1$0),(2-0-2),(1-1-6),(1-2-2)$ and (1-1-4) planes of $\mathrm{Fe}_{2} \mathrm{O}_{3}$, respectively. On the basis of XRD pattern, it can be concluded that prepared $\mathrm{Fe}_{3} \mathrm{O}_{4}$ is crystalline and pure in nature. In the XRD pattern of $\mathrm{Ag}-\mathrm{Fe}_{3} \mathrm{O}_{4}$ (Figure 1b) two additional diffraction peaks, one at $2 \theta 38.36$ and other at

Bull. Chem. Soc. Ethiop. 2020, 34(1) 
$64.61^{\circ}$, can be observed. Furthermore, the intensity of diffraction peaks at $2 \theta 44.36^{\circ}$ has been increased in XRD pattern of $\mathrm{Ag}-\mathrm{Fe}_{3} \mathrm{O}_{4}$. These peaks are indexed to (3-1-1), (2-2-0) and (2-2-2) hkl planes of Ag face centered cubic unit cell. $33.5 \mathrm{~nm}$ was calculated as average crystallite size of synthesized material using Scherrer formula, Eq. 1, ( $\beta$ : width of peak, $\theta$ : Bragg's angle) [3, 11, 13-15].

Particle size $=\frac{0.89 \times 0.154}{\beta \cos \theta}$

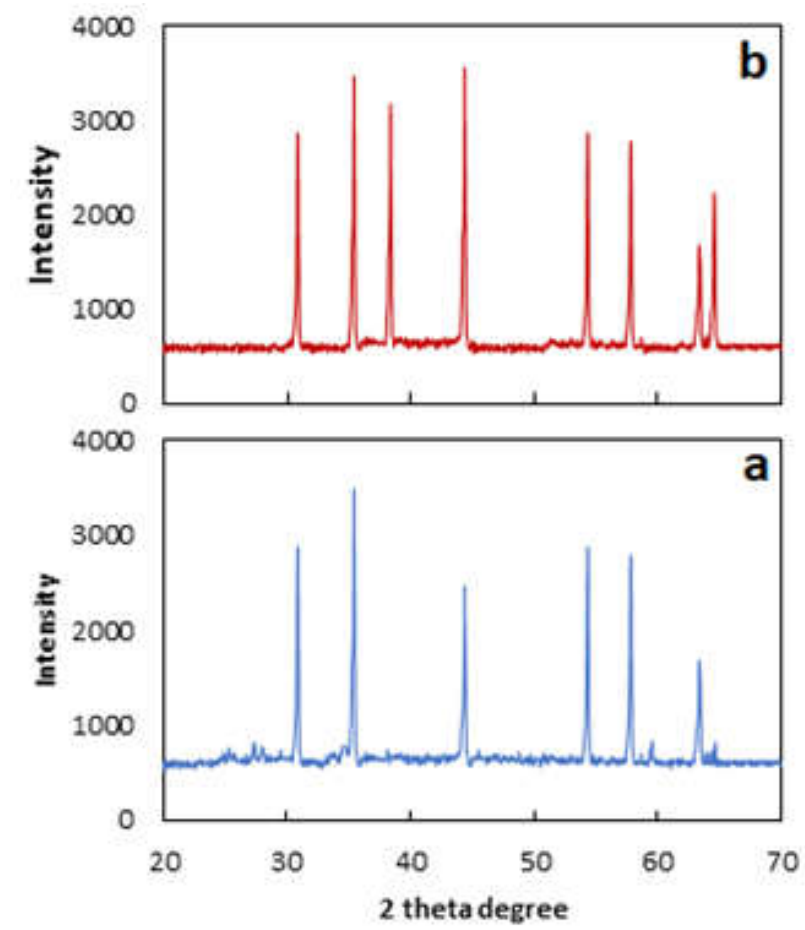

Figure 1. X-Rays analyses of $\mathrm{Fe}_{3} \mathrm{O}_{4}(\mathrm{a})$ and $\mathrm{Ag}-\mathrm{Fe}_{3} \mathrm{O}_{4}(\mathrm{~b})$.

The formation of $\mathrm{Fe}_{3} \mathrm{O}_{4}$ and $\mathrm{Ag}-\mathrm{Fe}_{3} \mathrm{O}_{4}$ was further supported by EDX analyses. Two peaks were observed in EDX spectrum of $\mathrm{Fe}_{3} \mathrm{O}_{4}$ as given in (Figure 2a) which represent the existence of iron and oxygen only with 70.76 and 29.24 weight percentage. The observed results of EDX analysis confirm the formation of $\mathrm{Fe}_{3} \mathrm{O}_{4}$. It is also confirmed that the synthesized material does not contain any other impurities. The results of both techniques, XRD and EDX, support each other. Similarly, in EDX spectrum of $\mathrm{Ag}-\mathrm{Fe}_{3} \mathrm{O}_{4}$ (Figure 2b) peaks for iron, oxygen and silver can be observed indicating the purity of prepared material.

Thermal stability of the prepared $\mathrm{Fe}_{3} \mathrm{O}_{4}$ and $\mathrm{Ag}-\mathrm{Fe}_{3} \mathrm{O}_{4}$ was studied by thermal gravimetric analysis (TGA) (Figure 3). It is concluded that the prepared photo catalyst is stable over a wide range of temperature as no appreciable loss on weight of the sample was noted with temperature over $30-600{ }^{\circ} \mathrm{C}$. About $8 \%$ weight loss was observed in TGA analysis of $\mathrm{Fe}_{3} \mathrm{O}_{4}$ (Figure 3a) up to $250{ }^{\circ} \mathrm{C}$ which corresponds to evaporation of moisture. Similarly, two weight losses were observed in TGA analysis of $\mathrm{Ag}-\mathrm{Fe}_{3} \mathrm{O}_{4}$ (Figure 3b). First weight loss of about $12 \%$ up to $250{ }^{\circ} \mathrm{C}$ can be attributed to evaporation of adsorbed water content while the other weight loss of $47 \%$ up to $350{ }^{\circ} \mathrm{C}$ represent the degradation of unwashed plant material.

Bull. Chem. Soc. Ethiop. 2020, 34(1) 

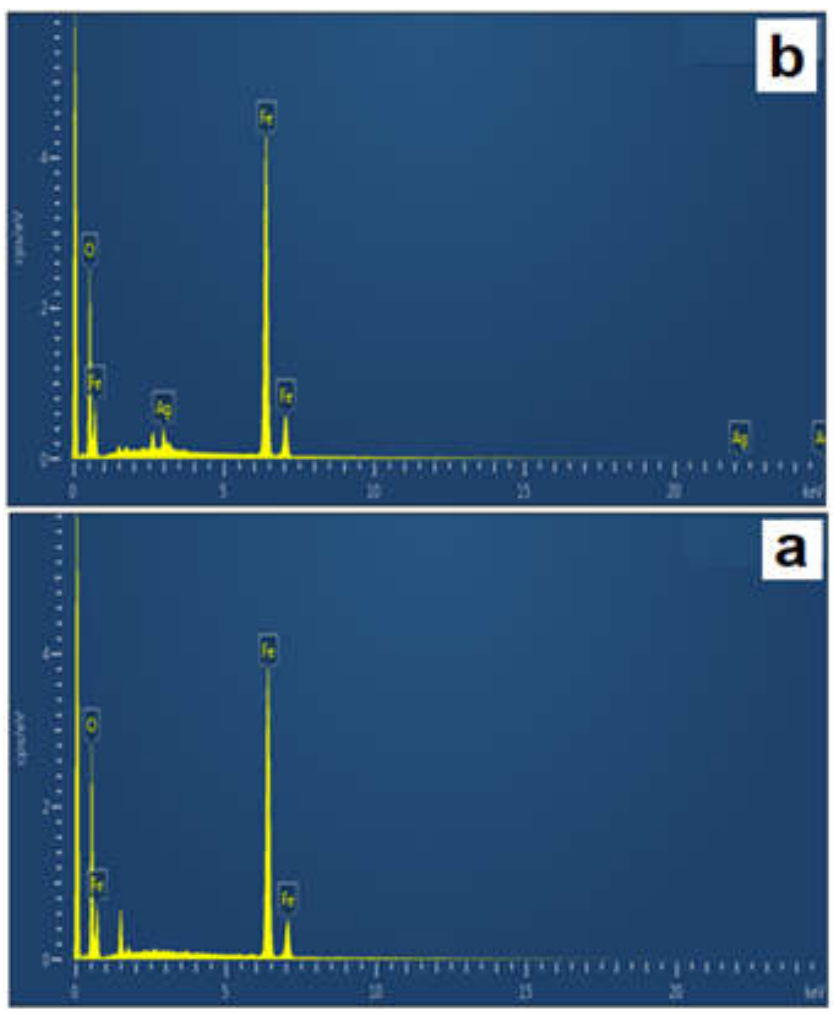

Figure 2. EDX spectrum of $\mathrm{Fe}_{3} \mathrm{O}_{4}$ (a) and $\mathrm{Ag}-\mathrm{Fe}_{3} \mathrm{O}_{4}(\mathrm{~b})$.

The shape of the prepared $\mathrm{Fe}_{3} \mathrm{O}_{4}$ and $\mathrm{Ag}-\mathrm{Fe}_{3} \mathrm{O}_{4} \mathrm{NPs}$ was investigated by SEM analyses. Considering the micrographs given in Figure 4, it is concluded that prepared particles are dispersed and non-agglomerated. Furthermore, the particles are homogeneous and spherical in shape.

Catalytic activity of synthesized $\mathrm{Fe}_{3} \mathrm{O}_{4}$ and $\mathrm{Ag}-\mathrm{Fe}_{3} \mathrm{O}_{4}$

The catalytic activity of synthesized $\mathrm{Fe}_{3} \mathrm{O}_{4}$ and $\mathrm{Ag}-\mathrm{Fe}_{3} \mathrm{O}_{4}$ was evaluated by visible light assisted photo degradation of methylene blue. The catalytic activity of prepared $\mathrm{Fe}_{3} \mathrm{O}_{4}$ and $\mathrm{Ag}-\mathrm{Fe}_{3} \mathrm{O}_{4}$ on degradation of methylene blue was estimated from measurement of absorbance/optical density of reaction mixture after every $10 \mathrm{~min}$. It was found that absorbance at $\lambda=630 \mathrm{~nm}$ continuously decreased as it is treated with $\mathrm{Fe}_{3} \mathrm{O}_{4} / \mathrm{Ag}-\mathrm{Fe}_{3} \mathrm{O}_{4}$. The decrease in absorbance shows the degradation of dye. The degradation of dye is expressed in a plot of $A_{t} / A_{0}\left(A_{t}=\right.$ absorbance of reaction mixture treated with photo catalyst for different time, $\mathrm{A}_{0}=$ absorbance of un-treated reaction mixture) against time as given in Figure 5. It is suggested that photo catalytic degradation of methylene blue dye reported here takes place in two stages. First, the degradation of dye proceeds slowly with generation of the $\mathrm{OH}$ radicals as suggested by slight decrease in absorbance with an induction period. The second stage of reaction is dominated with a significant decrease in absorbance. This stage represents degradation reaction where $\mathrm{OH}$ radicals mineralize the dye molecules [16]. The degradation of $0.0188 \mathrm{M}(50 \mathrm{~mL})$ dye solution 
obtained after treatment of dye with $\mathrm{Fe}_{3} \mathrm{O}_{4}$ and $\mathrm{Ag}-\mathrm{Fe}_{3} \mathrm{O}_{4}$ for 120 min was 41 and $73 \%$, respectively. To confirm the photo chemical reaction, degradation procedure was repeated in the absence of irradiation under similar conditions. It was observed that treatment of dye solution in the absence of light did not cause any significant change in concentration as given in Figure 6 . A small decrease in concentration of dye in the dark is due to adsorption of dye on the surface of catalyst. Therefore, the reaction mixture was stirred for 15 minutes in dark to get the adsorption equilibrium. Moreover, methylene blue was degraded in the presence of $\mathrm{Fe}_{3} \mathrm{O}_{4} / \mathrm{Ag}-\mathrm{Fe}_{3} \mathrm{O}_{4}$ catalyst due to $\mathrm{OH}$ radical. Irradiation of photo catalyst leads to formation of $\mathrm{OH}$ radical by a series of reactions of positive hole and photo excited electron pair $\left(\mathrm{h}^{+} / \mathrm{e}^{-}\right)$. These $\mathrm{OH}$ radical are active and unstable species which react with methylene blue and mineralize it. The proposed mechanism is described by following reactions $[13,17,18]$ :

$$
\begin{aligned}
& \mathrm{Fe}_{3} \mathrm{O}_{4}+\mathrm{hv} \rightarrow \mathrm{Fe}_{3} \mathrm{O}_{4}\left(h^{+}+e^{-}\right) \\
& h^{+}+\mathrm{H}_{2} \mathrm{O} \rightarrow \mathrm{OH}+\mathrm{H}^{+} \\
& e^{-}+\mathrm{O}_{2} \rightarrow \mathrm{O}_{2}^{-1} \\
& \mathrm{O}_{2}^{-1}+2 \mathrm{H}^{+} \rightarrow 2 \mathrm{OH} \\
& \mathrm{OH}+\text { Dye molecule } \rightarrow \text { Degradation products }
\end{aligned}
$$

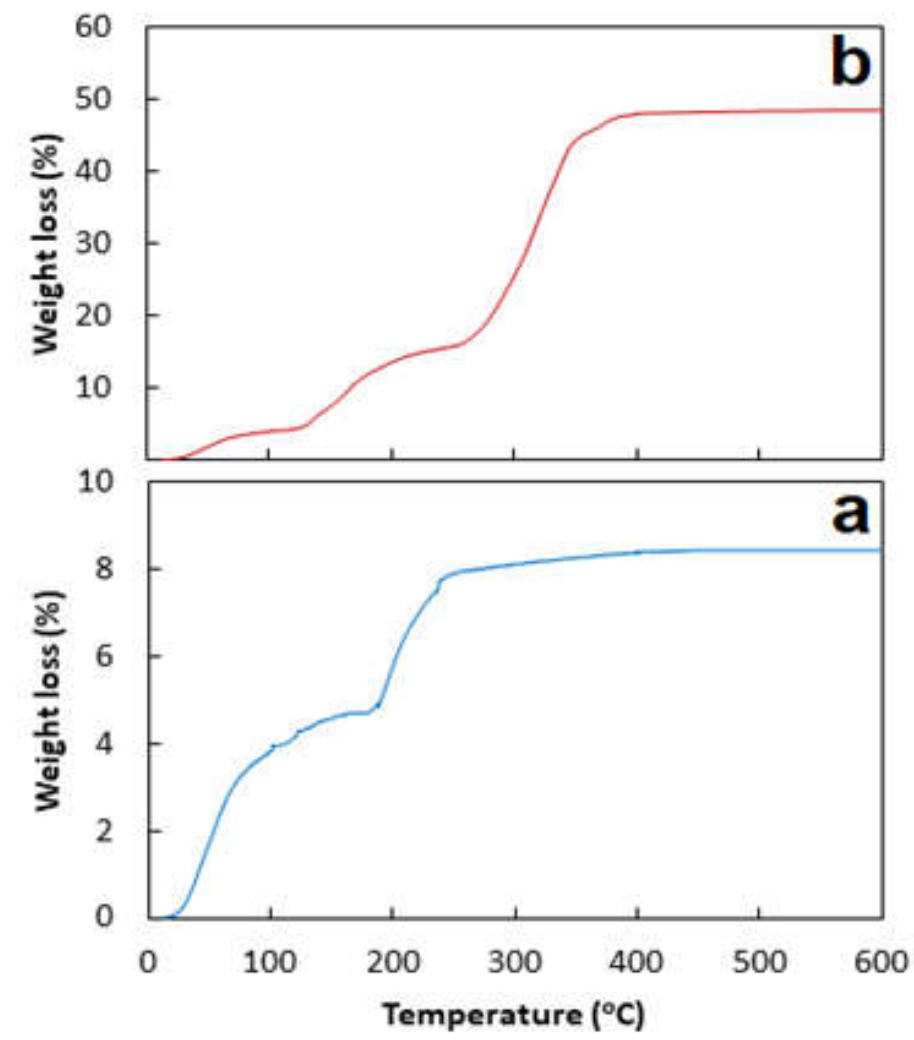

Figure 3. Thermal analysis of $\mathrm{Fe}_{3} \mathrm{O}_{4}(\mathrm{a})$ and $\mathrm{Ag}-\mathrm{Fe}_{3} \mathrm{O}_{4}(\mathrm{~b})$.

Bull. Chem. Soc. Ethiop. 2020, 34(1) 


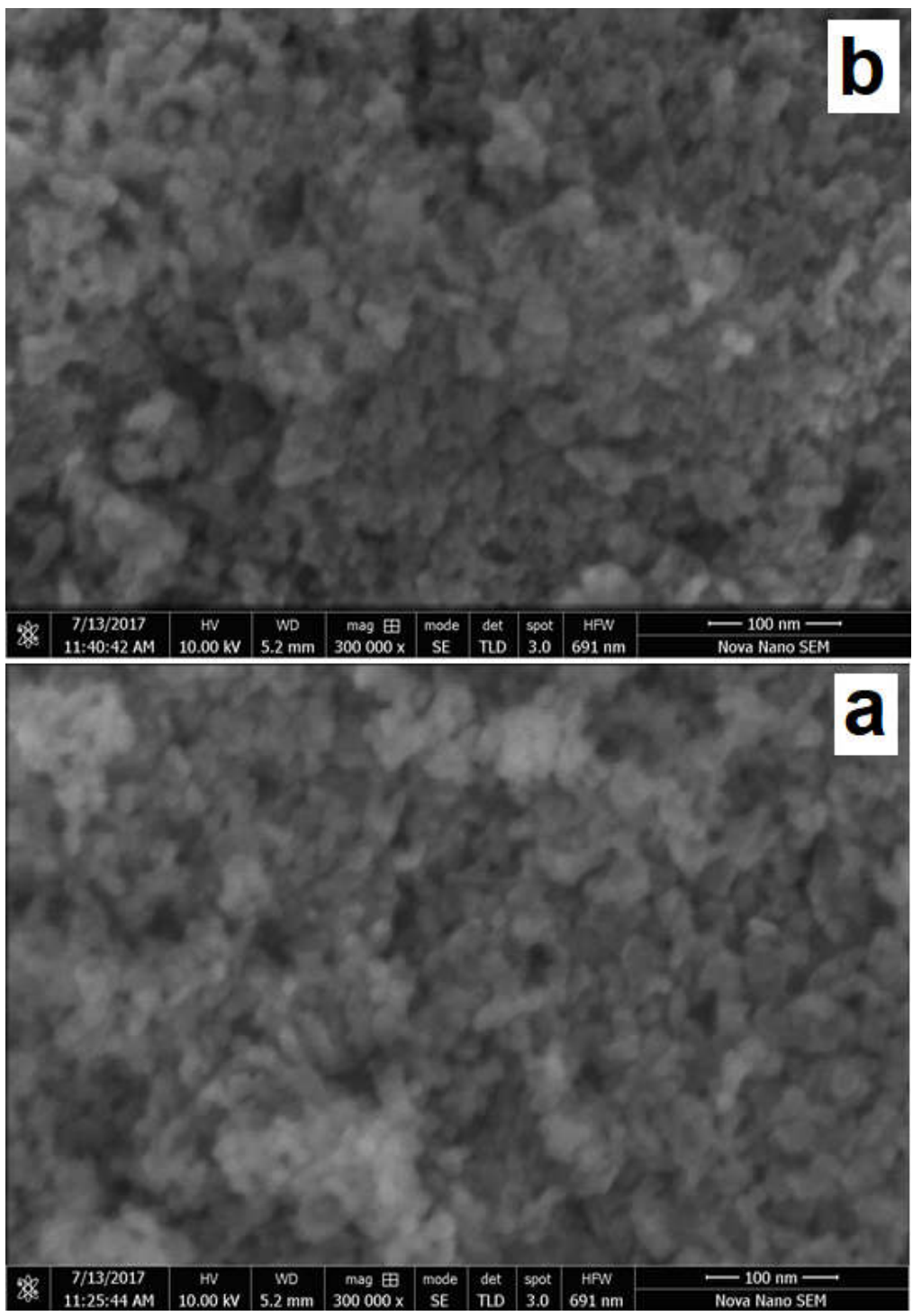

Figure 4. Scanning electron micrograph of $\mathrm{Fe}_{3} \mathrm{O}_{4}(\mathrm{a})$ and $\mathrm{Ag}-\mathrm{Fe}_{3} \mathrm{O}_{4}(\mathrm{~b})$. 


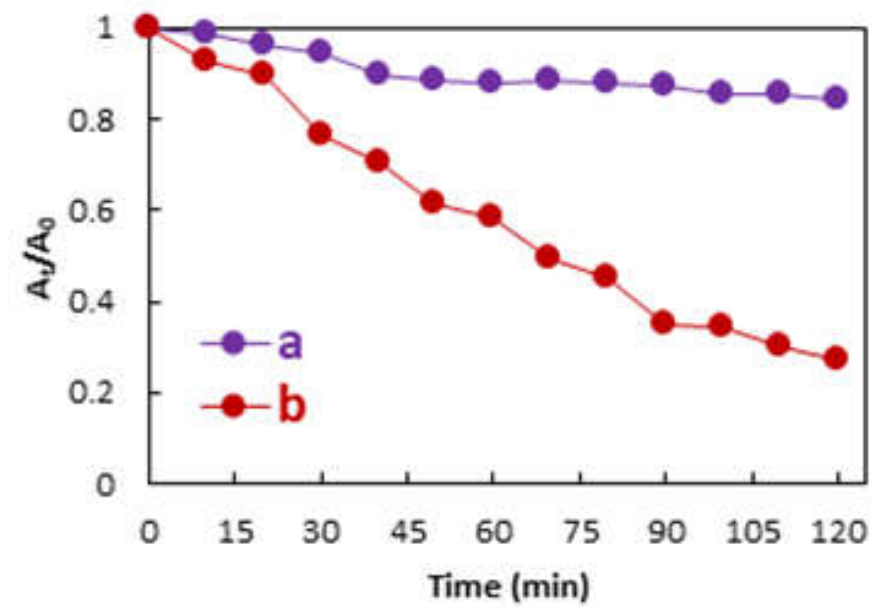

Figure 5. Decolorization of methylene blue treated with $\mathrm{Fe}_{3} \mathrm{O}_{4}(\mathrm{a})$ and $\mathrm{Ag}-\mathrm{Fe}_{3} \mathrm{O}_{4}$ (b) under visible irradiation $(50 \mathrm{~mL}$ of $0.0188 \mathrm{M}$ of methylene blue solution was irradiated over $0.1 \mathrm{~g}$ of catalyst at $\left.40^{\circ} \mathrm{C}\right)$.

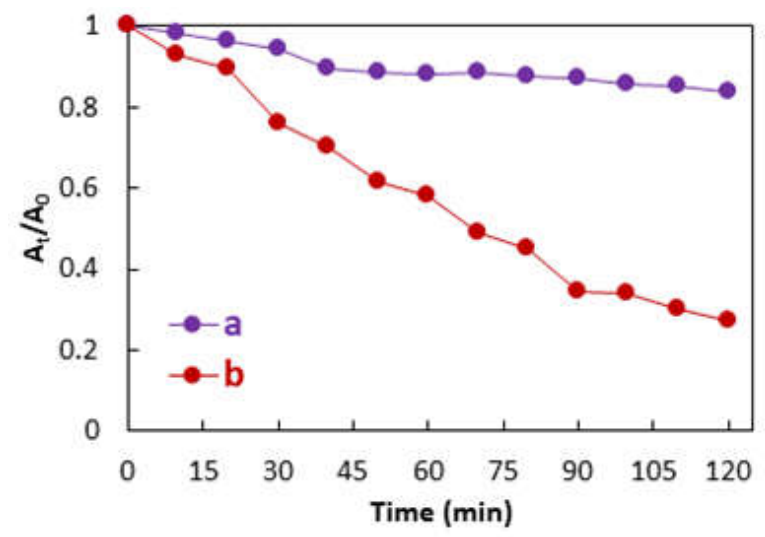

Figure 6. Decolorization of methylene blue treated with $\mathrm{Ag}-\mathrm{Fe}_{3} \mathrm{O}_{4}$ in dark (a) and light (b) (50 $\mathrm{mL}$ of $0.0188 \mathrm{M}$ of methylene blue solution was treated over $0.1 \mathrm{~g}$ of $\mathrm{Ag}-\mathrm{Fe}_{3} \mathrm{O}_{4}$ at 40 $\left.{ }^{\circ} \mathrm{C}\right)$.

Immobilization of $\mathrm{Ag}$ boosts up the catalytic performance of $\mathrm{Fe}_{3} \mathrm{O}_{4}$ towards degradation of methylene blue dye. These $\mathrm{Ag}$ nanoparticles immobilized on $\mathrm{Fe}_{3} \mathrm{O}_{4}$ act as electron traps resulting in decreasing the recombination of positive holes and electrons [19]. Hence the deposition of $\mathrm{Ag}$ on $\mathrm{Fe}_{3} \mathrm{O}_{4}$ improves the catalytic activity of $\mathrm{Fe}_{3} \mathrm{O}_{4}$. The possibility of proposed mechanism was confirmed by using isopropyl alcohol as $\mathrm{OH}$ radical scavenger [20].

The dependency of catalytic activity of $\mathrm{Ag}-\mathrm{Fe}_{3} \mathrm{O}_{4}$ on temperature was also studied. Typically, separate degradation reactions of methylene blue were conducted with $0.1 \mathrm{~g} \mathrm{Ag}$ $\mathrm{Fe}_{3} \mathrm{O}_{4}$ and $0.0188 \mathrm{M}(50 \mathrm{~mL})$ solution of methylene blue at 30,40 and $50{ }^{\circ} \mathrm{C}$ under visible 
irradiation. The analyses of reaction mixtures after 120 min showed that about 56,67 and $78 \%$ of dye degraded at 30,40 and $50{ }^{\circ} \mathrm{C}$, respectively. The degradation data obtained at different temperatures is given in Figure 7.

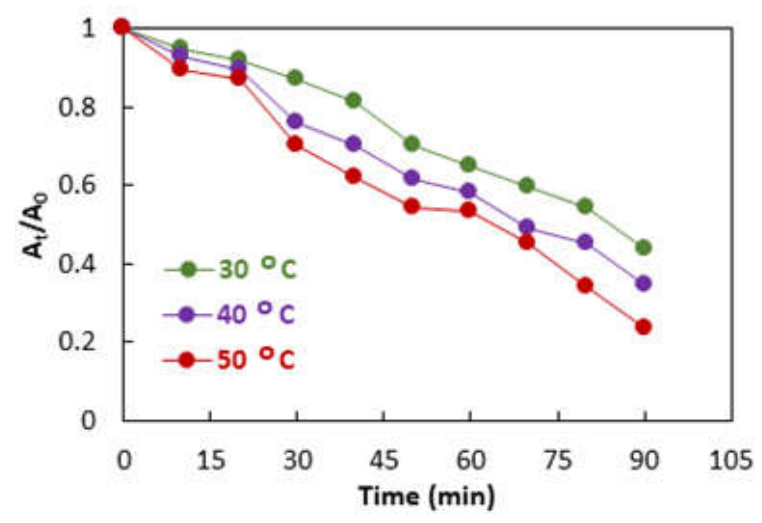

Figure 7. $\mathrm{Ag}-\mathrm{Fe}_{3} \mathrm{O}_{4}$ catalyzed photo degradation of methylene blue at various temperatures (50 $\mathrm{mL}$ of $0.0188 \mathrm{M}$ of methylene blue solution was irradiated over $0.1 \mathrm{~g}$ of $\mathrm{Ag}-\mathrm{Fe}_{3} \mathrm{O}_{4}$ ).

The degradation kinetics in present study is described by Eley-Rideal mechanism which suggests that the molecule of methylene blue dye reacts with adsorbed oxygen [21-26]. The proposed mechanism can be expressed mathematically in Eq. 2 as given below. Considering the constant pressure of oxygen, Eq. 2 can be written as Eq. 3, which changes to Eq. 4 on integration. The final mathematical expression, Eq. 4, is first order kinetics equation

$-\frac{d[M O]}{d t}=k_{r} O_{2(a d)}[M B]$

$-\frac{d[M O]}{d t}=k[M B]$

$\ln \frac{M B_{O}}{M B_{t}}=k t$

The degradation data of methylene blue at various temperatures was analyzed according to kinetic expression, Eq. 4. The results obtained by this analysis are given in Figure 8. On the basis of best straight lines in this figure (Figure 8), we conclude that photo degradation of methylene blue over $\mathrm{Ag}-\mathrm{Fe}_{3} \mathrm{O}_{4}$ in this study follow the pseudo-first-order kinetic model. The apparent rate constants determined from the slops of straight lines are 0.0076, 0.0102 and 0.0131 per min at 30,40 and $50{ }^{\circ} \mathrm{C}$, respectively. Other researchers have also reported similar kinetics analyses [27-34]. $22.2 \mathrm{~kJ} / \mathrm{mol}$ was calculated as energy of activation using the Arrhenius plot. As photo reactions are not much temperature dependent, therefore the activation energy is low. 


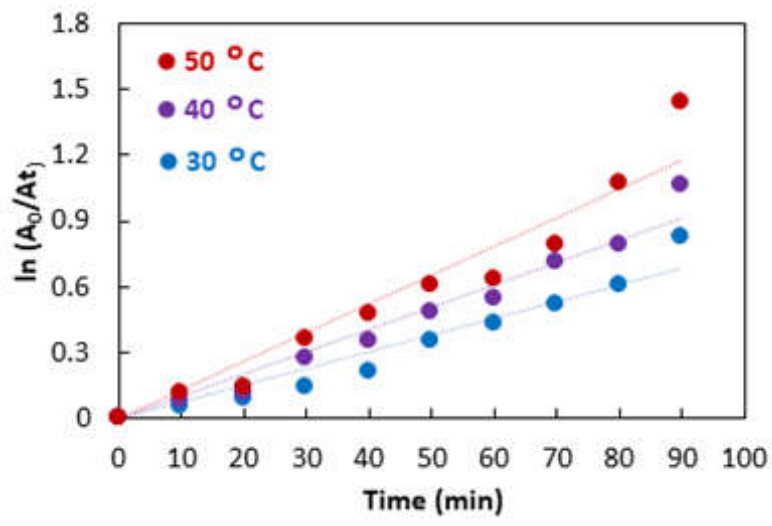

Figure 8. Kinetics analysis of $\mathrm{Ag}-\mathrm{Fe}_{3} \mathrm{O}_{4}$ catalyzed photo degradation of methylene blue at various temperatures.

Similarly, the dependency of catalytic activity of $\mathrm{Ag}-\mathrm{Fe}_{3} \mathrm{O}_{4}$ on initial concentration of dye was also studied. Typically, separate degradation reactions of methylene blue were conducted at $40{ }^{\circ} \mathrm{C}$ with $0.1 \mathrm{~g} \mathrm{Ag}-\mathrm{Fe}_{3} \mathrm{O}_{4}$ using a $50 \mathrm{~mL}$ solution of methylene blue having concentration $0.0063,0.0125$ and $0.0188 \mathrm{M}$. The analyses of reaction mixtures after $120 \mathrm{~min}$ showed that about 93,85 and $73 \%$ of the dye degraded with $0.0063,0.0125$ and $0.0188 \mathrm{M}$, respectively. The data obtained is given in Figure 9. The degradation data with various initial concentrations of methylene blue was analyzed according to Eq. 4 and the obtained results are given in Figure 10. The best straight lines suggest the pseudo first order kinetics in this study as stated earlier. The apparent rate constants determined from the slops of straight lines are 0.0207, 0.0138 and 0.0102 per min with $0.0063,0.0125$ and $0.0188 \mathrm{M}$, respectively. High concentration of dye imparts an intense color to solution which suppress the infiltration of photon to the solution resulting a decrease in rate of reaction. Hence increase in concentration of dye decreases the rate of reaction $[35,36]$.

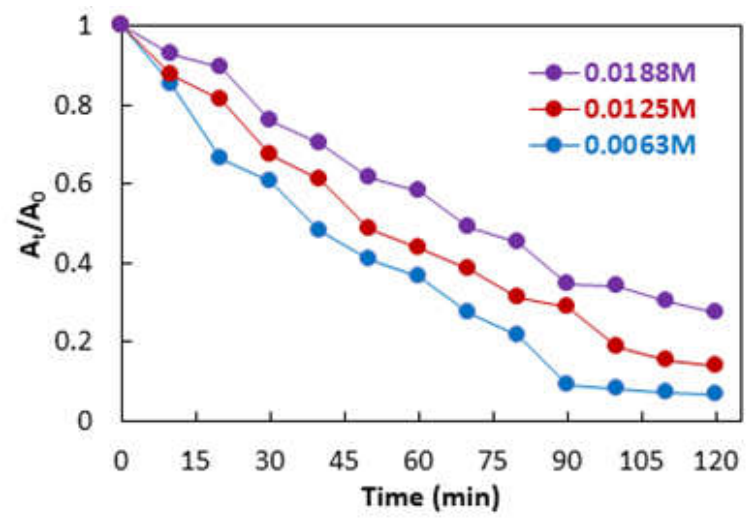

Figure 9. $\mathrm{Ag}-\mathrm{Fe}_{3} \mathrm{O}_{4}$ catalyzed degradation with various concentration of methylene blue $(50 \mathrm{~mL}$ of methylene blue solution was irradiated over $0.1 \mathrm{~g}$ of $\mathrm{Ag}-\mathrm{Fe}_{3} \mathrm{O}_{4}$ at $40{ }^{\circ} \mathrm{C}$ ).

Bull. Chem. Soc. Ethiop. 2020, 34(1) 


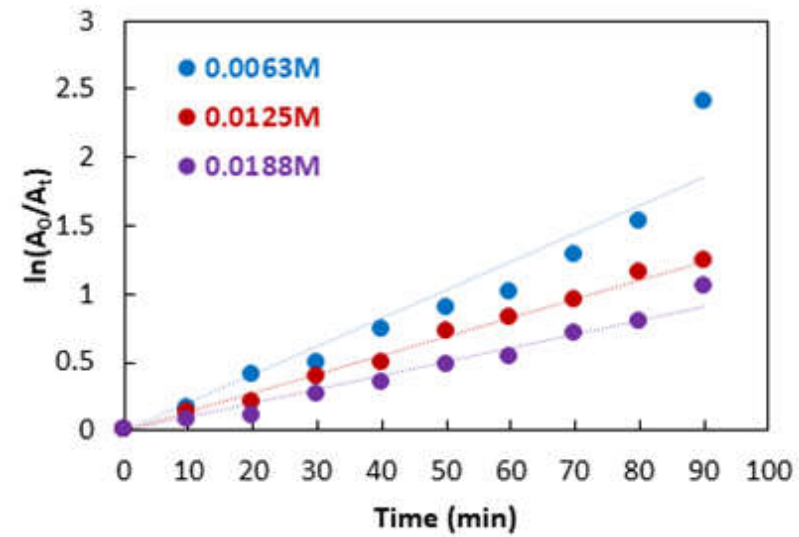

Figure 10. Kinetics analysis $\mathrm{Ag}-\mathrm{Fe}_{3} \mathrm{O}_{4}$ catalyzed photo degradation with various concentration of methylene blue dye.

\section{CONCLUSION}

$\mathrm{Ag}-\mathrm{Fe}_{3} \mathrm{O}_{4}$ were successfully synthesized and characterized by various techniques. The synthesized $\mathrm{Ag}-\mathrm{Fe}_{3} \mathrm{O}_{4}$ was used as photo catalyst for degradation of methylene blue dye in aqueous medium. The immobilization of $\mathrm{Ag}$ nanoparticles on $\mathrm{Fe}_{3} \mathrm{O}_{4}$ remarkable enhanced the photo catalytic activity of $\mathrm{Fe}_{3} \mathrm{O}_{4}$ towards photo degradation of methylene blue dye. It was found that 41 and $73 \%$ of $0.0188 \mathrm{M}$ degraded under visible irradiation in 120 min over $\mathrm{Fe}_{3} \mathrm{O}_{4}$ and $\mathrm{Ag}$ $\mathrm{Fe}_{3} \mathrm{O}_{4}$ as photo catalysts, respectively.

\section{ACKNOWLEDGMENTS}

Thanks to Government College University Faisalabad Pakistan and The World Academy of Sciences, Italy, for assistance under GCUF-RSP and COMSTECH-TWAS, respectively.

\section{REFERENCES}

1. Hariani, P.L.; Faizal, M.; Marsi, R.; Setiabudidaya, D. Synthesis and properties of $\mathrm{Fe}_{3} \mathrm{O}_{4}$ nanoparticles by co-precipitation method to removal procion dye. Int. J. Environ. Sci. Dev. 2013, 4, 336-340.

2. Chaki, S.H.; Malek, T.J.; Chaudhary, M.D.; Tailor, J.P.; Deshpande, M.P. Magnetite $\mathrm{Fe}_{3} \mathrm{O}_{4}$ nanoparticles synthesis by wet chemical reduction and their characterization. Adv. Nat. Sci. Nanosci. Nanotechnol. 2015, 6, 035009

3. Arularasu, M.V.; Devakumar, J.; Rajendran, T.V. An innovative approach for green synthesis of iron oxide nanoparticles: Characterization and its photocatalytic activity. Polyhedron 2018, 156, 279-290.

4. Guo, H.; Barnard. A.S. Thermodynamic modelling of nanomorphologies of hematite and goethite. J. Mater. Chem. 2011, 21, 11566-11577.

5. Radoń, A.; Drygała, A.; Hawełek, L.; Łukowiec, D. Structure and optical properties of $\mathrm{Fe}_{3} \mathrm{O}_{4}$ nanoparticles synthesized by co-precipitation method with different organic modifiers. Mater. Charact. 2017, 131, 148-156.

6. Rezayan, A.H.; Mosavi, M.; Kheirjou, S.; Amoabediny, G.; Ardestani, M.S.; Mohammadnejad, J. Monodisperse magnetite $\left(\mathrm{Fe}_{3} \mathrm{O}_{4}\right)$ nanoparticles modified with water 
soluble polymers for the diagnosis of breast cancer by MRI method. J. Magn. Magn. Mater. 2016, 420, 210-217.

7. Arefi, M.; Saberi, D.; Karimi, M.; Heydari, A. Superparamagnetic $\mathrm{Fe}(\mathrm{OH})_{3} @ \mathrm{Fe}_{3} \mathrm{O}_{4}$ nanoparticles: An efficient and recoverable catalyst for tandem oxidative amidation of alcohols with amine hydrochloride salts. ACS Comb. Sci. 2015, 17, 341-347.

8. Kalantari, K.; Ahmad, M.; Masoumi, H.; Shameli, K.; Basri, M.; Khandanlou, R. Rapid adsorption of heavy metals by $\mathrm{Fe}_{3} \mathrm{O}_{4} /$ talc nanocomposite and optimization study using response surface methodology. Int. J. Mol. Sci. 2014, 15, 12913-12927.

9. Sanaeifar, N.; Rabiee, M.; Abdolrahim, M.; Tahriri, M.; Vashaee, D.; Tayebi, L. A novel electrochemical biosensor based on $\mathrm{Fe}_{3} \mathrm{O}_{4}$ nanoparticles-polyvinyl alcohol composite for sensitive detection of glucose. Anal. Biochem. 2017, 519, 19-26.

10. Sadat, M.E.; Baghbador, M.K.; Dunn, A.W.; Wagner, H.P.; Ewing, R.C.; Zhang, J.; Xu, H.; Pauletti, G.M.; Mast, D.B.; Shi, D. Photoluminescence and photothermal effect of $\mathrm{Fe}_{3} \mathrm{O}_{4}$ nanoparticles for medical imaging and therapy. Appl. Phys. Lett. 2014, 105, 091903.

11. Haq, A.; Saeed, M.; Jamal, M.A.; Akram, N.; Bokhari, T.H.; Afaq, U. Green synthesis of $\mathrm{Ag}-\mathrm{NiO}$ and investigation of its catalytic activity for degradation of Rhodamine $\mathrm{B}$ dye in aqueous medium. Z. Phys. Chem. 2019, 233, 1047-1059.

12. Siddique, M.; Khan, N.M.; Saeed, M. Photocatalytic activity of bismuth ferrite nanoparticles synthesized via sol-gel route. Z. Phys. Chem. 2019, 233, 595-607.

13. Saeed, M.; Ahmad, A.; Boddula, R.; Din. I.; Haq, A.; Azhar, A. Ag@ $\mathrm{Mn}_{\mathrm{x}} \mathrm{O}_{\mathrm{y}}$ : An effective catalyst for photo-degradation of rhodamine B dye. Environ. Chem. Lett. 2018, 16, 287-294.

14. Wang. Y.; Sun, Y.; Li, W.; Tian, W.; Irini, A. High performance of nano scaled $\mathrm{Fe}_{2} \mathrm{O}_{3}$ catalyzing UV-Fenton under neutral condition with a low stoichiometry of $\mathrm{H}_{2} \mathrm{O}_{2}$ : Kinetic study and mechanism. Chem. Eng. J. 2015, 267, 1-8.

15. Arularasu, M.V.; Sundaram, R. Synthesis and characterization of nanocrystalline $\mathrm{ZnWO}_{4}$ $\mathrm{ZnO}$ composites and their humidity sensing performance. Sensing Biosens. Res. 2016, 11, 20-25.

16. Abhilasha, J.; Ashma, A.; Marazban, K. A greener approach for the degradation of dye methylene blue by organic additive catalysed photo-fenton process. J. Chil. Chem. Soc. 2016, 61, 3043-3048.

17. Jamal, A.; Rahman, M.M.; Khan, S.B.; Faisal, M.; Akhtar, K.; Rub, M.A.; Asiri, A.M.; AlYoubi, O.A. Cobalt doped antimony oxide nano-particles based chemical sensor and photocatalyst for environmental pollutants. Appl. Surf. Sci. 2012, 261, 52-58.

18. Saeed, M.; Muneer, M.; Mumtaz, N.; Siddique, M.; Akram, N.; Humayun, M. Ag- $\mathrm{Co}_{3} \mathrm{O}_{4}$ : Synthesis, characterization and evaluation of its photo-catalytic activity towards degradation of rhodamine B dye in aqueous medium. Chin. J. Chem. Eng. 2018, 26, 1264-1269.

19. Vartooni, A.R.; Nasrollahzadeh, M.; Niasari, M.S.; Atarod, M. Photocatalytic degradation of azo dyes by titanium dioxide supported silver nanoparticles prepared by a green method using Carpobrotus acinaciformis extract. J. Alloys Comp. 2016, 689, 15-20.

20. Jo, W.K.; Kumar, S.K.; Isaacs, M.A.; Lee, A.F.; Karthikeyan, S. Cobalt promoted $\mathrm{TiO}_{2} / \mathrm{GO}$ for the photocatalytic degradation of oxytetracycline and Congo Red. Appl. Catal. B Environ. 2017, 201, 159-168.

21. Makwana, V.D.; Son, Y.C.; Howell, A.R.; Suib, S.L. The role of lattice oxygen in selective benzyl alcohol oxidation using OMS-2 catalyst: A kinetic and isotope-labeling study. $J$. Catal. 2002, 210, 46-52.

22. Lai, T.L.; Lee, C.C.; Wu, K.S.; Shu, Y.Y.; Wang, C.B. Microwave-enhanced catalytic degradation of phenol over nickel oxide. Appl. Catal. B Environ. 2006, 68, 147-153.

23. Saeed, M.; Ilyas, M.; Siddique, M. Kinetics of lab prepared manganese oxide catalyzed oxidation of benzyl alcohol in the liquid phase. Int. J. Chem. Kin. 2015, 47, 447-460. 
24. Saeed, M.; Adeel, S.; Ilyas, M.; Shahzad, M.A.; Usman, M.; Haq, E.; Hamayun, M. Oxidative degradation of Methyl Orange catalyzed by lab prepared nickel hydroxide in aqueous medium. Desalin. Water Treat. 2016, 57, 12804-12813.

25. Saeed, M.; Haq, A.; Muneer, M.; Adeel, S.; Hamayun, M.; Ismail, M. Degradation of direct black 38 dye catalyzed by lab prepared Nickel hydroxide in aqueous medium. Glob. NEST J. 2016, 18, 309-320.

26. Rahman, Q.I.; Ahmad. M.; Misra, S.K.; Lohani, M. Effective photocatalytic degradation of rhodamine B dye by $\mathrm{ZnO}$ nanoparticles. Mater. Lett. 2013, 91, 170-174.

27. Shah, N.S.; Khan, J.A.; Sayed, M.; Khan, Z.H.; Iqbal, J.; Arshad, S. Synergistic effects of $\mathrm{H}_{2} \mathrm{O}_{2}$ and $\mathrm{S}_{2} \mathrm{O}_{8}{ }^{2-}$ in the gamma radiation induced degradation of congo-red dye: Kinetics and toxicities evaluation. Sep. Purif. Technol. 2020, 233, 115966-11975.

28. Iqbal, J.; Shah, N.S.; Sayed, M.; Muhammad, N.; Rehman, S.; Khan, A.; Khan, Z.H.; Howari, F.M.; Nazza, Y.; Xavier, C.; Arshad, S.; Hussein, A.; Polychronopoulou, K. Deep eutectic solvent-mediated synthesis of ceria nanoparticles with the enhanced yield for photocatalytic degradation of flumequine under UV-C. J. Water Proc. Eng. 2020, 33, 101012-101019.

29. Shah, N.S.; Khan, J.A.; Sayed, M.; Khan, Z.H.; Iqbal, J.; Imran, M.; Murtaza, B.; Zakir, A.; Polychronopoulou, K. Nano zerovalent zinc catalyzed peroxymonosulfate based advanced oxidation technologies for treatment of chlorpyrifos in aqueous solution: A semi-pilot scale study. J. Cleaner Prod. DOI: 10.1016/j.jclepro.2019.119032.

30. Shah, N.S.; Khan, J.A.; Sayed, M.; Khan, Z.H.; Rizwan, A.D.; Muhammad, M.; Boczkaj, G.; Murtaza, B.; Imran, M.; Khan, H.M.; Zaman, G. Solar light driven degradation of norfloxacin using as-synthesized $\mathrm{Bi}^{3+}$ and $\mathrm{Fe}^{2+}$ co-doped $\mathrm{ZnO}$ with the addition of $\mathrm{HSO}_{5}^{-}$: Toxicities and degradation pathways investigation. Chem. Eng. J. 2018, 351, 841-855.

31. Wu, W.P.; Liu, W.C.; Qiu, S.W.; Ma, A.Q.; Dai, W.; Qian, Y.; Kumar, A. Application of a water stable zinc(II) glutamate metal organic framework for photocatalytic degradation of organic dyes. Bull. Chem. Soc. Ethiop. 2019, 33, 43-50.

32. Khan, J.; Tariq, M.; Muhammad, M.; Mehmood, M.H.; Ullah, I.; Raziq, A.; Akbar, F. Saqib, M.; Rahim, A.; Niaz, A. Kinetic and thermodynamic study of oxidative degradation of acid yellow 17 dye by Fenton-like process: Effect of $\mathrm{HCO}_{3}{ }^{-}, \mathrm{CO}_{3}{ }^{2-}, \mathrm{Cl}^{-}$and $\mathrm{SO}_{4}{ }^{2-}$ on degradation. Bull. Chem. Soc. Ethiop. 2019, 33, 243-254.

33. Wu, W.P.; Ding, Q.; Wu, X.R.; Huang, Y.J.; Gong, C.; Huang, H.; Trivedi, M.; Kumar, A. Photocatalytic degradation of organic dyes by infinite one dimensional coordination polymer based on Zn(II) in water. Bull. Chem. Soc. Ethiop. 2019, 33, 51-60.

34. Punjabi, P.B.; Ameta, R.; Kumar, A.; Jain, M. Visible light induced photocatalytic degradation of some xanthene dyes using immobilized anthracene. Bull. Chem. Soc. Ethiop. 2008, 22, 361-368.

35. Davis, R.J.; Gainer, J.L.; Neal, G.; Wenwu, I. Photocatalytic decolourisation of wastewater dyes. Wat. Environ. Res. 1994, 66, 50-53.

36. Pare, B.; Jonnalagadda, S.B.; Tomar, H.; Singh, P.; Bhagwat, V.W. ZnO assisted photocatalytic degradation of acridine orange in aqueous solution using visible irradiation. Desalination 2008, 232, 80-90. 